\title{
Promoter methylation status and expression of PPAR- $\gamma$ gene are associated with prognosis of acute-on-chronic hepatitis B liver failure
}

\author{
Ze-Hua Zhao', Yu-Chen Fan ${ }^{1,2}$, Qi Zhao ${ }^{3}$, Cheng-Yun Dou' ${ }^{1}$ Xiang-Fen Ji ${ }^{1}$, Jing Zhao ${ }^{1}$, Shuai Gao ${ }^{1}$, Xin-You Li ${ }^{1}$ \\ and Kai Wang ${ }^{1,2^{*}}$
}

\begin{abstract}
Background: Peroxisome proliferator-activated receptor gamma (PPAR- - ) has been demonstrated to be involved in anti-inflammatory reactions, but its role in acute-on-chronic hepatitis B liver failure (ACHBLF) is unclear. Therefore, DNA methylation patterns and expression level of PPAR- $\gamma$ gene were detected in peripheral blood mononuclear cells (PBMCs) from 81 patients with ACHBLF, 50 patients with chronic hepatitis B (CHB), and 30 healthy controls, and the possible role of PPAR- $\gamma$ in ACHBLF was analyzed.

Results: We found that aberrant PPAR- $\gamma$ promoter methylation was attenuated in ACHBLF patients compared with $\mathrm{CHB}$ patients and was responsible for the elevated PPAR- $\gamma$ expression level, which was negatively correlated with total bilirubin and international normalized ratio. Plasma level of TNF- $a$ and IL-6 in ACHBLF patients were higher than CHB patients and healthy controls and significantly reduced in unmethylated group. ACHBLF patients with PPAR- $\gamma$ promoter methylation had poorer outcomes than those without. Correspondingly, PPAR- $\gamma$ messenger RNA (mRNA) level was higher in survivors than non-survivors and gradually increased in survivors with time, while remained low level in non-survivors.
\end{abstract}

Conclusions: Aberrant promoter methylation decline and PPAR- $y$ expression rebound occurred in ACHBLF compared with $\mathrm{CHB}$ and could improve prognosis of ACHBLF by negatively regulating cytokines.

Keywords: DNA methylation, Acute-on-chronic hepatitis B liver failure, Peroxisome proliferator-activated receptor gamma, Cytokines, Prognosis

\section{Background}

Hepatitis B virus (HBV) infection is one of the most serious public health problems, affecting more than two billion people worldwide. There are more than 350 million chronic carriers, $75 \%$ of whom reside in the Asia Pacific region [1]. Reactivation of HBV infection is a major cause for acute deterioration of liver function manifesting as jaundice and coagulopathy, which is a severe life-threatening condition termed acute-on-chronic hepatitis B liver failure (ACHBLF) [2]. It is demonstrated that pro-inflammatory and antiinflammatory cytokines play a crucial role in the pathogenesis of ACHBLF and constantly influence the disease

\footnotetext{
* Correspondence: wangdoc876@126.com

'Department of Hepatology, Qilu Hospital of Shandong University, Wenhuaxi Road 107\#, Jinan 250012, China

${ }^{2}$ Institute of Hepatology, Shandong University, Wenhuaxi Road 107\#, Jinan 250012, China

Full list of author information is available at the end of the article
}

progression. Level of several cytokines has been found to be elevated in patients with ACHBLF, which may be led to endotoxemia, cytokine release by necrotic liver cells, and/or reduced hepatic removal [2-6]. Consequently, elevated cytokines aggravate liver injury by mediating acute systemic inflammatory response and raise the fatality rate [6]. However, the exact mechanism of ACHBLF is not fully delineated.

Peroxisome proliferator-activated receptor gamma (PPAR- $\gamma$ ) is a member of nuclear receptor supergene family that functions in ligand-dependent transcription $[7,8]$. The PPAR- $\gamma$ is abundantly expressed in adipose tissue, colon, spleen, and macrophages and is believed to play a role in adipocyte differentiation, lipid metabolism, and glucose homeostasis by exerting effect on gene transcription [9-12]. Recently, accumulating evidence has demonstrated that PPAR- $\gamma$ is involved in anti- 
inflammatory reactions both in vitro and in vivo. Several studies have investigated the effects of PPAR- $\gamma$ activation on the inflammatory responses of monocytes and macrophages. It is shown that PPAR- $\gamma$ activation can inhibit the expression of the inducible nitric oxide synthase (iNOS), gelatinase $B$, and scavenger receptor A genes in response to PPAR- $\gamma$ ligands and can also inhibit inflammatory gene expression in part by antagonizing the activities of the transcription factors AP-1, STAT, and NF-kB in transfected cell lines [13, 14]. Additionally, it is revealed that PPAR- $\gamma$ functions to dampen inflammation and injury and synthetic agonists remarkably activate PPAR- $\gamma$ and amplify the effect in animal models of acute lung injury [15]. Similar results are observed in colitis [16] and acute pancreatitis [17] in vivo. All these findings suggest that PPAR- $\gamma$ may serve as an anti-inflammatory mediator and play a protective role in inflammatory diseases.

In our previous study, we found PPAR- $\gamma$ was significantly down-regulated due to promoter hypermethylation, and its expression level was correlated with intrahepatic fibrosis and inflammation grade in patients with chronic hepatitis B (CHB) [18]. ACHBLF is quite a different situation from $\mathrm{CHB}$, which is basically a transition from the chronic phase into the fulminant phase and manifests as a process of acute decompensation of liver function. Considering the widely different mechanisms underlying the two situations, it is still of great importance to examine the role of PPAR- $\gamma$ in ACHBLF. Therefore, it arouses our interest to detect the change of promoter methylation status and expression of PPAR- $\gamma$ gene and its possible role in the acute event.

Therefore, the current study aimed to determine the promoter methylation patterns and expression of PPAR- $\gamma$ gene and plasma level of inflammatory cytokines in patients with ACHBLF to explore the role of PPAR- $\gamma$ in the progression and prognosis of ACHBLF and test its possibility to be used as a biomarker for prediction and surveillance.

\section{Results}

\section{General characteristics of subjects}

The selection process for subjects enrolled is shown in Additional file 1: Figure S1. Eventually, 81 ACHBLF patients, $50 \mathrm{CHB}$ patients, and 30 healthy controls were enrolled in the present study. The demographic and clinical characteristics are shown in Table 1.

\section{Methylation frequency of PPAR- $\gamma$ promoter in patients with ACHBLF}

We first detected the methylation status of two CpG islands in PPAR- $\gamma$ promoter in all enrolled subjects (Table 2). The methylation frequency of PPAR- $\gamma$ promoter in ACHBLF patients was significantly decreased compared with CHB patients (CpG-1, $\chi^{2}=8.918, P=0.003$; CpG-2, $\left.X^{2}=9.268, P=0.002\right)$, however, was still greatly higher than healthy controls (CpG-1, $X^{2}=6.691, P=0.009$; CpG$\left.2, X^{2}=5.050, P=0.025\right)$. Also, we found that methylation frequency of both $\mathrm{CpG}$ islands in $\mathrm{CHB}$ patients was prominently higher than healthy controls $\left(\mathrm{CpG}-1, \chi^{2}=21.333\right.$,

Table 1 Baseline characteristics of the subjects enrolled in the study

\begin{tabular}{|c|c|c|c|}
\hline & ACHBLF & $\mathrm{CHB}$ & $\mathrm{HC}$ \\
\hline Cases (n) & 81 & 50 & 30 \\
\hline Age (years) & $44.25 \pm 13.65$ & $41.80 \pm 14.04$ & $41.57 \pm 12.09$ \\
\hline Gender (m/f) & $57 / 24$ & $35 / 15$ & $21 / 9$ \\
\hline $\mathrm{HBeAg}(+/-)$ & $37 / 44$ & $23 / 27$ & $0 / 30$ \\
\hline $\log _{10}[\mathrm{HBV}$ DNA] & $5.16 \pm 1.71$ & $5.64 \pm 1.64$ & NA \\
\hline $\operatorname{ALT}(\mathrm{U} / \mathrm{L})$ & $489.45 \pm 642.68^{* * * *}$ & $362.92 \pm 470.21^{*}$ & $27.10 \pm 11.55$ \\
\hline AST (U/L) & $398.61 \pm 534.34^{* * * * *}$ & $183.40 \pm 202.84^{*}$ & $26.77 \pm 7.34$ \\
\hline TBIL $(\mu \mathrm{mol} / \mathrm{L})$ & $296.43 \pm 158.18^{*, * *}$ & $30.19 \pm 38.44^{*}$ & $12.48 \pm 5.08$ \\
\hline $\mathrm{Cr}(\mu \mathrm{mol} / \mathrm{L})$ & $73.35 \pm 42.66^{* * * *}$ & $63.34 \pm 13.64^{*}$ & $57.33 \pm 12.79$ \\
\hline ALB (g/L) & $33.48 \pm 8.73^{*, * *}$ & $40.86 \pm 5.67^{*}$ & $47.00 \pm 4.53$ \\
\hline PTA (\%) & $37.84 \pm 9.06^{* * * *}$ & $91.94 \pm 17.39$ & $93.60 \pm 14.17$ \\
\hline INR & $1.87 \pm 0.63^{* * * *}$ & $1.02 \pm 0.14$ & $1.01 \pm 0.11$ \\
\hline Ascites (\%) & $76.54^{* * * *}$ & $24.00^{*}$ & 0 \\
\hline Encephalopathy (\%) & $34.57^{* * * *}$ & 0 & 0 \\
\hline Mortality (\%) & $54.32^{* * * *}$ & 0 & 0 \\
\hline
\end{tabular}

Data are shown as mean \pm standard deviation

$A C H B L F$ acute-on-chronic hepatitis B liver failure, $C H B$ chronic hepatitis $B, H C$ healthy control, HBV Hepatitis B virus, $A L T$ alanine aminotransferase, $A S T$ aspartate aminotransferase, TBIL total bilirubin, $C r$ serum creatinine, $A L B$ albumin, PTA prothrombin activity, INR international normalized ratio, NA not available *Versus HC $P<0.05 ; * *$ Versus CHB $P<0.05$ 
Table 2 A cross table for methylation status of two islands in all subjects

\begin{tabular}{|c|c|c|c|c|c|c|}
\hline & \multicolumn{2}{|c|}{ CpG-1 island } & \multirow[t]{2}{*}{ Total } & \multicolumn{2}{|c|}{ CpG-2 island } & \multirow[t]{2}{*}{ Total } \\
\hline & $\overline{M U}$ & $U$ & & $\overline{\mathrm{MU}}$ & $U$ & \\
\hline ACHBLF & 35 & 46 & 81 & 38 & 43 & 81 \\
\hline $\mathrm{CHB}$ & 35 & 15 & 50 & 37 & 13 & 50 \\
\hline $\mathrm{HC}$ & 5 & 25 & 30 & 7 & 23 & 30 \\
\hline Total & 75 & 86 & 161 & 82 & 79 & 161 \\
\hline
\end{tabular}

$M U$ for methylation and unmethylation states both presented, $U$ for only unmethylation status presented

$P<0.001$; CpG-2, $X^{2}=19.448, P<0.001$ ) (Fig. 1a), and this was identified with our former study.

Hypermethylation of CPG islands in PPAR- $\gamma$ gene promoter resulted in down-regulation

Due to the fact that alteration of promoter methylation status is a usual mechanism affecting transcriptional activity, we then measured the expression level of PPAR- $\gamma$. The messenger RNA (mRNA) level of PPAR- $\gamma$ in subjects with or without methylation was compared. The results showed that relative expression of PPAR- $\gamma$ was significantly decreased with either CpG-1 $(Z=-6.613, P<0.001)$ or CpG$2(Z=-7.712, P<0.001)$ island methylation (Fig. 1c, d), and the suppression seemed to be superposable (both MU vs. one MU, $Z=-4.085, P<0.001$ ) (Fig. 1e). The data confirmed our deduction and were basically in agreement with our previous study.

\section{Correlation between increased PPAR- $\gamma$ mRNA level and clinical parameters in patients with ACHBLF}

Moreover, we found that PPAR- $\gamma$ mRNA level was significantly elevated in ACHBLF patients compared with $\mathrm{CHB}$ patients $(Z=-4.003, P<0.001)$ (Fig. 2a). However, PPAR$\gamma$ mRNA level was significantly lower in ACHBLF patients than that in healthy controls $(Z=-4.632, P<0.001)$. Meanwhile, expression of PPAR- $\gamma$ was significantly lower in $\mathrm{CHB}$ patients than healthy controls $(Z=-6.037, P<$ $0.001)$. These results were corresponding with the alteration of promoter methylation status we observed and showed above. To further study the role of PPAR- $\gamma$ in ACHBLF, we combined with clinical data that reflected liver function of the patients. Linear correlation analysis showed that expression of PPAR- $\gamma$ was negatively correlated with total bilirubin (TBIL) $(r=-0.280, P=$ 0.011 , Fig. 2c) and international normalized ratio (INR) $(r=-0.230, P=0.039$, Fig. 2d). No significant correlation was found between PPAR- $\gamma$ mRNA level and alanine aminotransferase (ALT), creatinine (Cr), or HBV-DNA load in patients with ACHBLF (Fig. 2b, e, f). These data

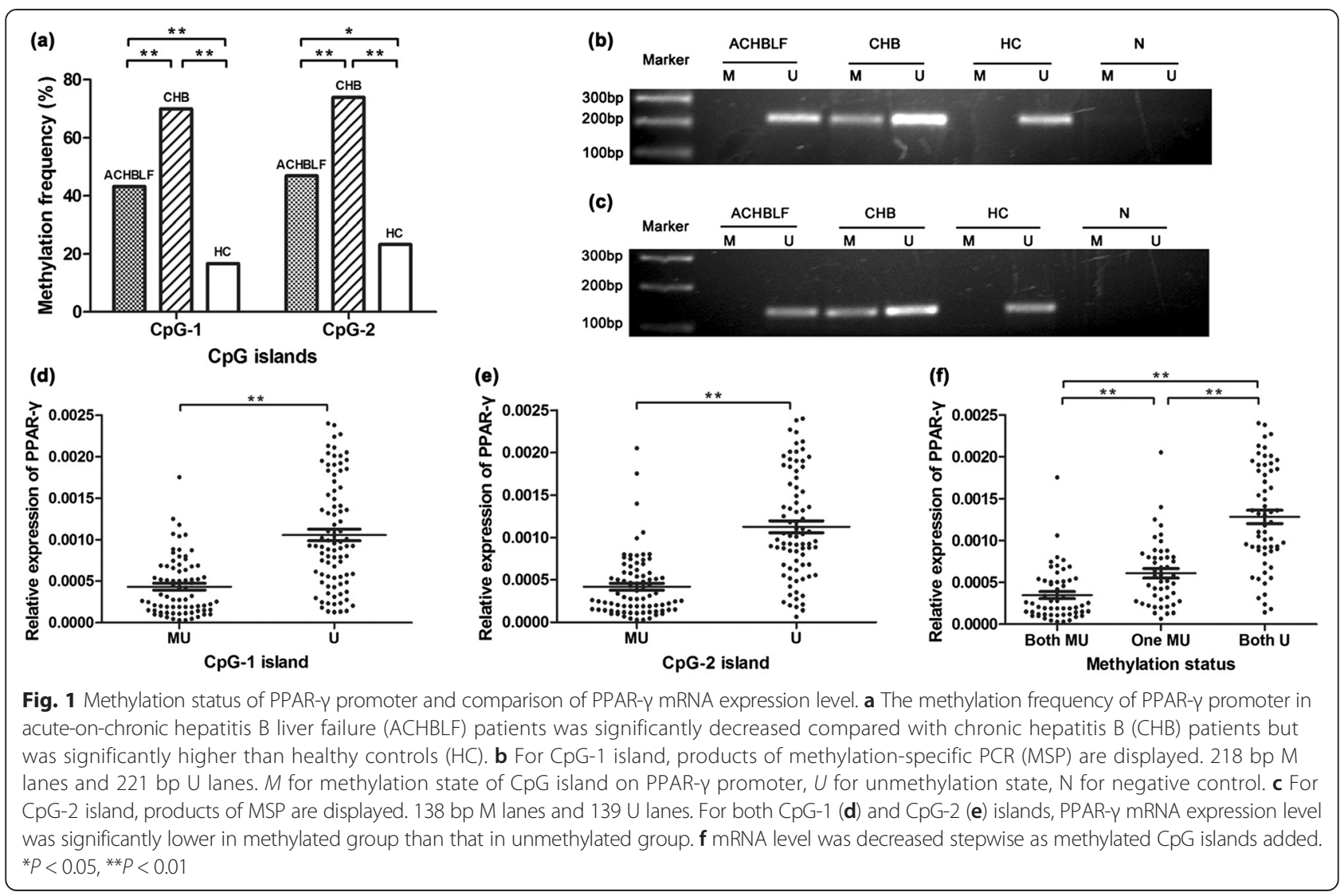




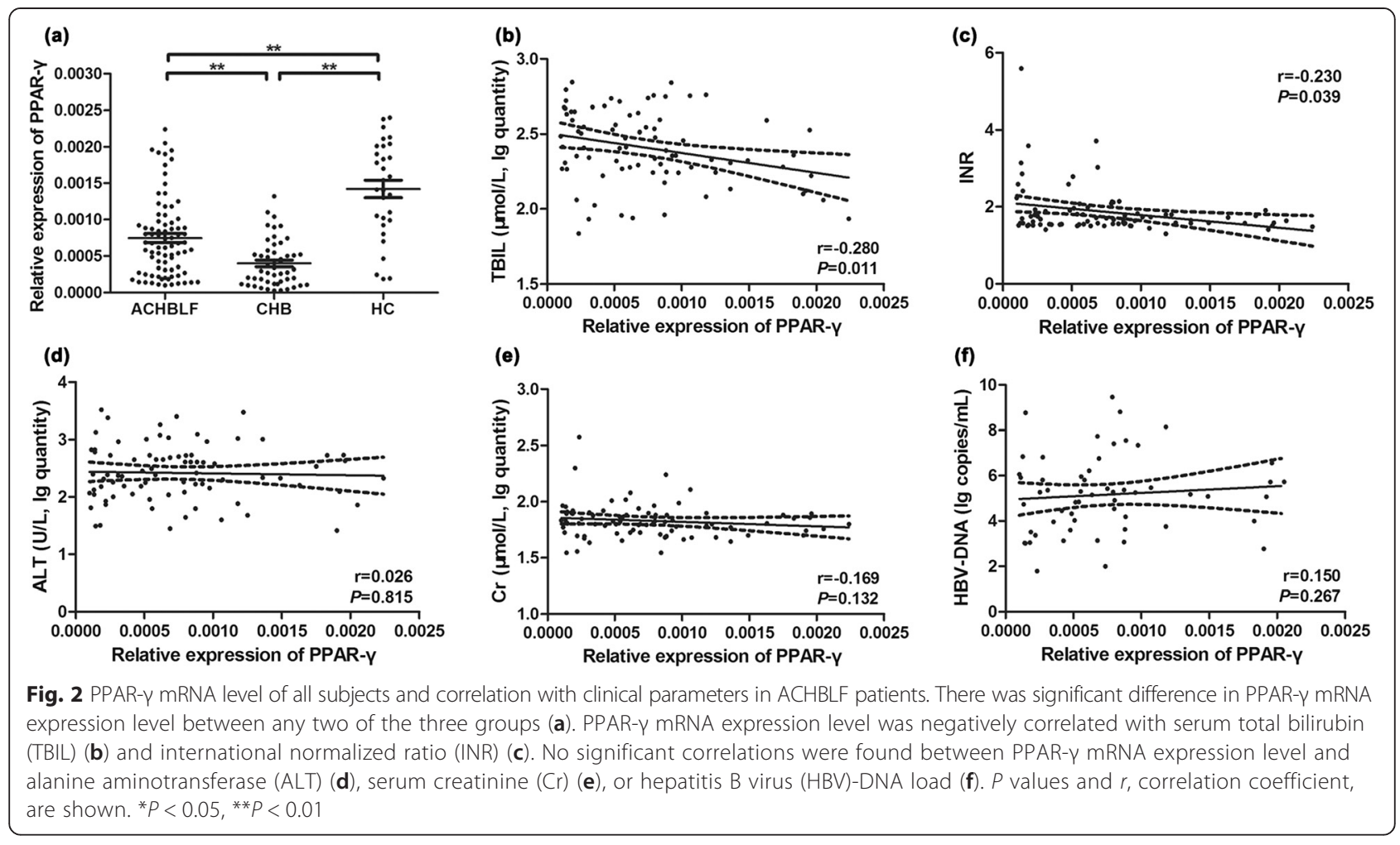

suggested that PPAR- $\gamma$ was closely related with the severity of ACHBLF.

\section{Level of cytokines and relation with PPAR- $\gamma$ promoter methylation in patients with ACHBLF}

Now that PPAR- $\gamma$ was shown to be involved in the disease, we tried to further study the probable mechanism. The plasma level of TNF- $\alpha$ and IL- 6 was assessed by enzyme-linked immunosorbent assay (ELISA) in the subjects. Level of both cytokines was significantly increased in ACHBLF patients compared with $\mathrm{CHB}$ patients (TNF- $\alpha, t=6.649, P<0.001$; IL-6, $t=6.784, P<$ 0.001 ) and healthy controls (TNF- $\alpha, t=5.582, P<0.001$; IL-6, $t=5.961, P<0.001$ ) (Fig. 3a, b). No significant difference in level of both cytokines was found between $\mathrm{CHB}$ patients and healthy controls. In patients with ACHBLF, level of plasma cytokines in methylated group was significantly higher than unmethylated group (TNF- $\alpha$, $t=2.312, P=0.023$; IL-6, $t=2.639, P=0.012$ ) (Fig. 3c). These results implied that relative elevation of PPAR- $\gamma$ expression as a result of promoter demethylation could effectively repress the pro-inflammatory cytokines.

\section{Association between PPAR- $\gamma$ promoter methylation and prognosis of patients with ACHBLF}

Considering the anti-inflammatory effect of PPAR- $\gamma$, we speculated that PPAR- $\gamma$ might alleviate the fulminant inflammatory injury and thus prolong the survival time of

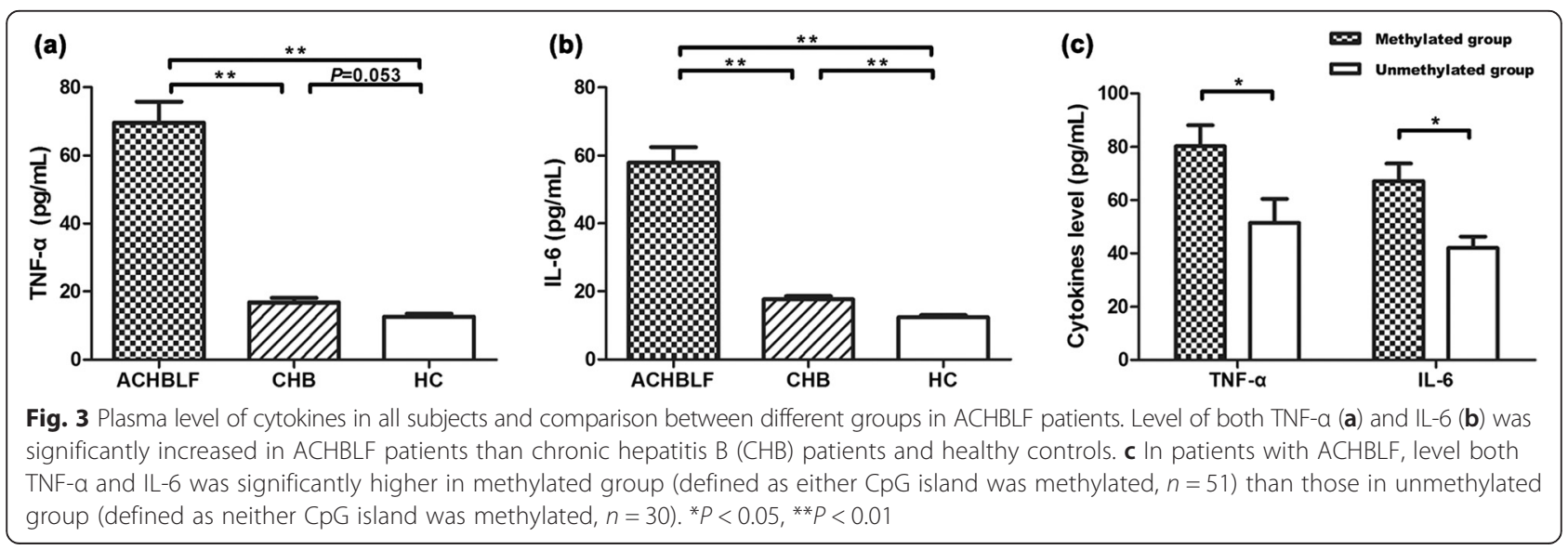


ACHBLF patients. So, a short-term follow-up was conducted. The 3-month mortality was $54.32 \%(44 / 81)$, and the mean survival time is 53.47 (SE 4.057, $95 \% \mathrm{CI}$ 45.39-61.54). The PPAR- $\gamma$ mRNA level of survivors was significantly higher than non-survivor $(Z=-3.489, P<$ 0.001, Fig. 4a). Kaplan-Meier survival curve for ACHBLF patients with or without PPAR- $\gamma$ methylation was demonstrated in Fig. 4b. Prognosis of methylated group was significantly poorer compared with unmethylated group $\left(\chi^{2}=11.140, P<0.001\right)$. The mean survival time for methylated group and unmethylated group was 42.24 days (SE 5.113, $95 \%$ CI 31.97-52.50) and 72.57 days (SE 5.101, $95 \%$ CI 62.13-83.00), respectively. A continuous surveillance of PPAR- $\gamma$ mRNA expression level was carried out in twenty-seven ACHBLF patients within the first 3 weeks after admission. Data of some non-survivors were incomplete due to the intermediate death. We noted that PPAR- $\gamma$ expression was significantly increased with time extending in survivors (Fig. 4c), while remained low level in non-survivors (Fig. 4d). The disparity between PPAR- $\gamma$ mRNA level of the two groups was expanded week by week (Fig. 4e). Because of the significant relation between PPAR- $\gamma$ and prognosis of the patients, we examined its potential use in clinical prediction. Prognostic performance was evaluated, and the receiver operating characteristic (ROC) curve for PPAR- $\gamma$ methylation, PPAR $-\gamma$
mRNA, and model for end-stage liver diseases (MELD) score was illustrated (Fig. 4f). The areas under the ROC curve (AUC) were 0.726 (SE 0.059, $95 \%$ CI 0.611-0.841), 0.657 (SE 0.062, $95 \%$ CI 0.535-0.778), and 0.725 (SE 0.056, $95 \%$ CI 0.615-0.836), respectively.

\section{Discussion}

In this study, we firstly reported the alteration of PPAR- $\gamma$ promoter methylation status and gene expression in peripheral blood mononuclear cells (PBMCs) in patients with ACHBLF. We found that promoter methylation frequency was decreased and mRNA level of PPAR- $\gamma$ was elevated in ACHBLF patients when comparing with $\mathrm{CHB}$ patients. Plasma level of TNF- $\alpha$ and IL- 6 prominently rose in patients with ACHBLF and both cytokines level were lower in unmethylated group than methylated group. Moreover, promoter methylation status and mRNA level of PPAR- $\gamma$ were closely associated with prognosis of patients with ACHBLF in the 3-month follow-up. The unmethylated group, which also meant the group with higher PPAR- $\gamma$ expression level, showed a better outcome than the methylated group. Dynamic observation showed that PPAR- $\gamma$ expression level was elevated in survivors while remained low level in non-survivors.

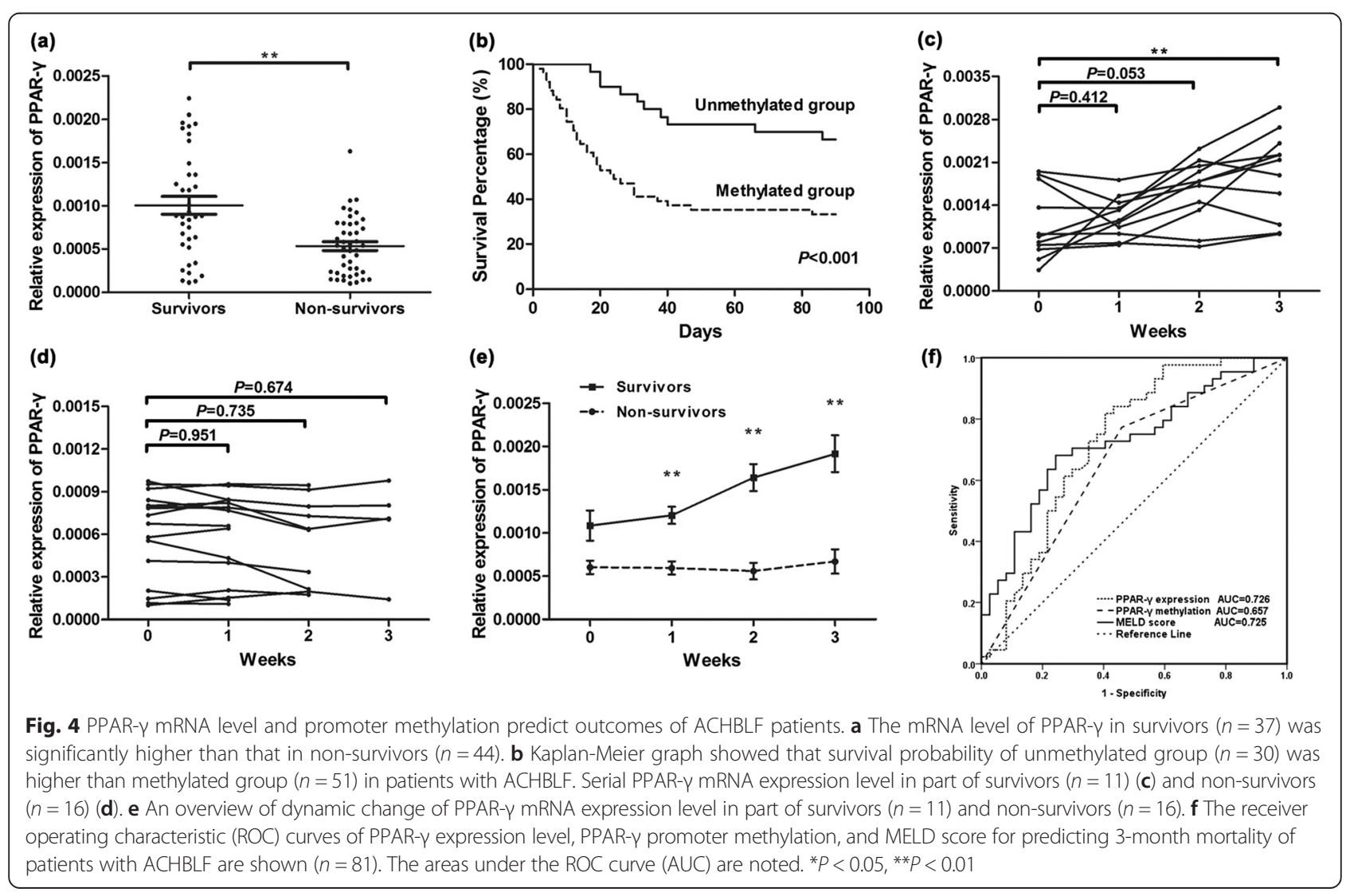


CpG islands refer to DNA segments which are abundant in $\mathrm{CpG}$ content, and $\mathrm{CpG}$ islands usually locate in the promoters $[19,20]$. Methylation of CpG islands in gene promoter is an important regulating pattern of gene expression and usually results in gene silencing [21]. In our previous study, we had already found that hypermethylation of promoter was an important mechanism in PPAR- $\gamma$ gene silencing and synchronous methylation of the two $\mathrm{CpG}$ islands might exert more powerful inhibition of gene transcription. The present data provided further confirmation of the conclusion. Meanwhile, the decreased methylation frequency was corresponding with the elevated PPAR- $\gamma$ expression level in ACHBLF patients.

We had known that PPAR- $\gamma$ expression was significantly down-regulated due to the hypermethylation occurred in promoter of $\mathrm{CHB}$ in our former study. Compared with CHB patients, we found that mRNA level of PPAR- $\gamma$ was elevated in ACHBLF patients. However, the rebound was limited and failed to reach the normal level in comparison with health controls, which meant the inhibitory effect still existed with HBV infection. This phenomenon revealed the immune system disorder in ACHBLF and could be one of the mechanisms which contributed to the onset and exacerbation of the disease.

Although the pathogenesis of ACHBLF still remains to be elucidated, the important role played by cytokines has been long focused. It is believed that imbalanced expression of pro-inflammatory and anti-inflammatory cytokines may contribute to immunopathogenesis in ACHBLF. Among them, TNF- $\alpha$ and IL- 6 are two key cytokines. It was reported that TNF- $\alpha$ production was increased in acute liver failure (ALF) [22, 23]. Zou et al. found that intrahepatic expression of TNF- $\alpha$ was closely correlated with the intrahepatic $\mathrm{CD}^{+} \mathrm{CD}^{+} \mathrm{T}$ lymphocytes and Kupffer cells (KCs) cellular infiltration in ACHBLF [5]. It has also been shown that TNF- $\alpha$ level in ALF correlated subsequent serious clinical complications, such as infection and encephalopathy [24-26]. Gazzard et al. reported elevated IL-6 level with multiple organ failures and increased mortality in ALF [27]. A recent study found that IL- 6 may be involved in ACHBLF by upregulating Th17 response which mediates massive tissue inflammation by recruiting immune cells [28]. Moreover, it has been reported that activation of PPAR- $\gamma$ could inhibit production of inflammatory cytokines by monocytes [14]. In agreement with the above studies, we found that plasma level of TNF- $\alpha$ and IL- 6 in ACHBLF patients were dramatically higher than $\mathrm{CHB}$ patients and healthy controls, and level of both cytokines declined in unmethylated group compared with methylated group, which meant elevation of PPAR- $\gamma$ expression level could lead to decreasing of proinflammatory cytokines. Taken together, we speculated that PPAR- $\gamma$ gene expression elevation due to the attenuation of promoter methylation could be a self-protective measure under inflammatory stress by down-regulating level of TNF- $\alpha$ and IL- 6 which were involved in immunemediated liver injury in ACHBLF.

Therefore, PPAR- $\gamma$ is supposed to be closely related with prognosis of patients with ACHBLF, which was confirmed by our 3-month follow-up. Patients without PPAR- $\gamma$ methylation had better chances to survive. PPAR- $\gamma$ mRNA level was higher and continuously elevated in survivors, while lower and sustained at low level in non-survivors with time extending. Thus, we evaluated the performance of PPAR- $\gamma$ to predict prognosis of patients with ACHBLF. Although PPAR- $\gamma$ methylation $(\mathrm{AUC}=0.657$ ) was poorer than MELD score (AUC $=0.725)$, PPAR- $\gamma$ expression (AUC $=0.726$ ) was comparable to MELD score and could be regarded as a valuable prognostic marker. Still, more studies focusing on the prognostic performance of PPAR$\gamma$ are needed to verify the conclusion.

According to the Asian Pacific Association for the Study of Liver (APASL) practice guideline, inhibition of the inflammatory cytokines might offer a novel approach for reducing the morbidity and mortality in patients with ACHBLF due to the fact that cytokines influence the development and course of ACHBLF [2]. Our study suggested that PPAR- $\gamma$ might serve as a candidate treatment target for the possibility that activation of PPAR- $\gamma$ could downregulate pro-inflammatory cytokines and improve the prognosis of patients with ACHBLF. Chemically synthesized PPAR- $\gamma$ agonists, such as thiazolidines, can selectively activate PPAR- $\gamma$ to increase the peripheral sensitivity to insulin and reduce the blood glucose level and are commonly used to treat type 2 diabetes. Recently, increasing investigations have been focused on therapeutic value of PPAR- $\gamma$ agonists in inflammatory diseases treatment. Suh et al. reported that PPAR- $\gamma$ ligands inhibited epithelial inflammatory response in animal models of colitis, and Bordji et al. reported the anti-inflammatory properties of PPAR- $\gamma$ ligands in ameliorating the cytokine-induced damage to cartilage associated with arthritis $[29,30]$. Therefore, it is likely that PPAR- $\gamma$ agonists are of therapeutic value to some extent in ACHBLF treatment. Despite all this, more investigations are needed to confirm the conjecture.

There are some limitations in this study. Firstly, our sample size is relatively small, which may cause a low Spearman's rho value in the correlation analysis. However, ACHBLF is a sever condition with high mortality but low morbidity which makes it difficult to recruit a large number of patients rapidly, and the low Spearman's rho value is attributed to not only relative number of patients but also other multiple factors including the basal liver function, heterogeneity of underlying diseases, and hepatic compensative capacity, which would greatly affect the alteration of clinical parameters. Still, more studies with a large scale in different cohorts are expected to validate our results. Secondly, as discussed above, in vivo and in 
vitro experiments with PPAR- $\gamma$ agonists intervention are imperative to explore the therapeutic value of PPAR- $\gamma$ agonists in ACHBLF.

The interpretation is very interesting when retrospecting the findings of our former study. PPAR- $\gamma$ was believed to be involved in hepatic stellate cells (HSCs) activation and differentiation which was a core event in liver fibrosis and was a pivotal gene to maintain the adipogenic phenotype characteristics of HSCs and prevent the initiation of fibrosis [31]. Our former study also confirmed that silencing of PPAR- $\gamma$ due to the promoter hypermethylation contributed to the onset and progression of liver fibrosis in $\mathrm{CHB}$ patients. Whereas, another important part of PPAR- $\gamma$ was demonstrated in our present study that it was actually involved in anti-inflammation reactions by repressing level of pro-inflammatory cytokines such as TNF- $\alpha$ and IL-6 and was a protective factor in ACHBLF. So, the predominant biological functions of PPAR- $\gamma$ in different diseases were indeed various and crucial. Furthermore, a recent study has revealed that PPAR- $\gamma$ seems to be involved in the epigenetic regulation of miR-122 whose gene transcription is enhanced as a result of increased affinity of PPAR $-\gamma$ and retinoid $X$ receptor alpha (RXR $\alpha)$ complex to the gene promoter in hepatocellular carcinoma cells [32]. In turn, PPAR- $\gamma$ could also be regulated in a microRNAdependent way [33]. It is demonstrated that downregulation of miR-132 can promote the formation of an epigenetic repressor complex inhibiting PPAR- $\gamma$ expression and therefore promoting liver fibrosis in vivo [34]. These new findings suggest an exquisite role of PPAR- $\gamma$ in epigenetic regulation in the liver diseases and provide new promising fields in which more mechanisms could be shed light on and better efforts to improve clinical practice might be made.

\section{Conclusions}

In conclusion, we found decreased methylation frequency and elevated PPAR- $\gamma$ expression level of PPAR- $\gamma$ promoter in ACHBLF patients compared with CHB patients. Promoter methylation and expression level of PPAR- $\gamma$ were closely associated with severity and prognosis of ACHBLF. Also, PPAR- $\gamma$ may have a potential role in improving prognosis of patients with ACHBLF by down-regulating TNF- $\alpha$ and IL-6.

\section{Methods}

\section{Patients and controls}

Eighty-one patients with ACHBLF, 50 patients with CHB, and 30 healthy controls were recruited from July 2010 to January 2015 at Department of Hepatology, Qilu Hospital of Shandong University. Patients with ACHBLF were defined according to the consensus recommendation of the APASL [2]. To be specific, patients with acute hepatic insult manifesting as jaundice (serum bilirubin $\geq 5 \mathrm{mg} / \mathrm{dl}$
[85 $\mu \mathrm{mol} / \mathrm{L}]$ ) and coagulopathy (INR $\geq 1.5$ or prothrombin activity $<40 \%$ ), complicated within 4 weeks by ascites and/or encephalopathy based on $\mathrm{CHB}$, were considered eligible. Patients with $\mathrm{CHB}$ were defined as presence of hepatitis B s antigen (HBsAg) in serum last for more than 6 months, and there was histological evidence of chronic hepatitis, according to the 2009 update of American Association for the Study of Liver Diseases (AASLD) practice guidelines for management of chronic hepatitis B [35]. Patients were excluded if they met any of the following criteria: (1) co-infected with HCV or HIV, (2) suffered from other liver diseases such as autoimmune hepatitis and alcoholic hepatitis, (3) receiving antioxidant agent or interferon therapy, (4) pregnant, and (5) complicated with hepatocellular carcinoma. A 3-month follow-up was conducted, and the outcomes were recorded in patients with ACHBLF. The start date was defined as the date of diagnosis of ACHBLF after hospital admission. There was no ACHBLF patient received liver transplantation in the study. Prior to sample collection, informed consent was obtained from each participant, and the study was approved by the local Ethical Committee of Qilu Hospital of Shandong University.

\section{Plasma collection and PBMCs isolation}

Five milliliters of venous peripheral blood was collected from each subject, using EDTA as anticoagulant agent. Plasma was collected after centrifugation and stored at $-80{ }^{\circ} \mathrm{C}$ for detection of cytokines. PBMCs were isolated by gradient centrifugation via Ficoll-Paque (Pharmacia Diagnostics, Uppsala, Sweden) according to the manufacturer's protocol and were stored at $-20{ }^{\circ} \mathrm{C}$ until use.

\section{DNA and RNA extraction from PBMCs}

Genomic DNA was extracted from PBMCs using QIAamp DNA Blood Mini Kit (QIAGEN, Valencia, CA, USA) following the protocol provided by manufacturer and stored at $-20{ }^{\circ} \mathrm{C}$. Total RNA was extracted by phenol-chloroform-isopropanol method, purified, and resuspended in $20 \mu \mathrm{L}$ of RNase-free water.

\section{Sodium bisulfate modification and MSP}

The extracted DNA was treated with sodium bisulfite using an EZ DNA methylation Kit (Zymo Research, Orange, CA, USA) and then subjected to methylationspecific polymerase chain reaction (MSP). Four pairs of primers were used specifically to detect the PPAR- $\gamma$ gene promoter methylation status. The conditions for PCR amplification were 40 cycles consisting of $30 \mathrm{~s}$ at $95{ }^{\circ} \mathrm{C}$ for denaturation, $40 \mathrm{~s}$ at $54.5{ }^{\circ} \mathrm{C}$ (CpG-1 island), or $52{ }^{\circ} \mathrm{C}$ (CpG-2 island) for annealing and $30 \mathrm{~s}$ at $72{ }^{\circ} \mathrm{C}$ for extension. The PCR products were separated via a $2.0 \%$ agarose gel and visualized under UV illumination 
after staining with ethidium bromide. Primers were designed based on the upstream sequence of PPAR- $\gamma$ gene [GenBank: NC_000003.12 (12287850-12471013)] (Additional file 2: Figure S2), which were described in our previous study [18] and listed in Additional file 3: Table S1.

\section{RT-PCR}

Total RNA (1 $\mu$ g per reaction) was converted into complementary DNA (cDNA) with PrimerScript" RT Reagent Kit (Perfect Real Time; Takara, Japan) according to the manufacturer's instruction, with condition of $70{ }^{\circ} \mathrm{C}$ for $5 \mathrm{~min}$ for denaturation and $42{ }^{\circ} \mathrm{C}$ for $60 \mathrm{~min}$ for reverse transcription. The cDNA production was subjected to realtime quantitative PCR (RT-PCR) to detect level of PPAR- $\gamma$ mRNA, and $\beta$-actin was used as the endogenous control. The RT-PCR amplification mixtures $(10 \mu \mathrm{L})$ included $0.5 \mathrm{mM}$ each primer, $10 \times$ SYBR Green (Toyobo, Osaka, Japan) and $0.5 \mu \mathrm{L}$ cDNA. The real-time PCR was performed as follows: the initial step was $95{ }^{\circ} \mathrm{C}$ for $30 \mathrm{~s}$, followed by 40 cycles of $95{ }^{\circ} \mathrm{C}$ for $5 \mathrm{~s}, 60^{\circ} \mathrm{C}$ for $30 \mathrm{~s}$ and $72{ }^{\circ} \mathrm{C}$ for $30 \mathrm{~s}$. Data analysis was performed with the LightCycler Software 4.0 (Roche Diagnostics, Germany), and results were determined using the comparative $\left(2^{-\Delta \mathrm{Ct}}\right.$, $\Delta \mathrm{Ct}=\mathrm{Ct}(\mathrm{PPAR}-\gamma)-\mathrm{Ct}(\beta$-actin $))$ method.

\section{ELISA for detection of plasma TNF- $a$ and IL- 6 level}

Level of plasma cytokines was measured using Human Tumor necrosis factor $\alpha$ ELISA Kit and Human Interleukin 6 ELISA Kit (EIAab, Wuhan, China), according to the standard protocols of the manufacturer. The minimum detectable dose was typically $3.9 \mathrm{pg} / \mathrm{mL}$ for TNF- $\alpha$ and $7.80 \mathrm{pg} / \mathrm{mL}$ for IL-6, respectively.

\section{Clinical parameters}

Fasting venous blood was collected from each subject. Hepatitis B s antigen (HBsAg) and hepatitis B e antigen (HBeAg) were detected by an electrochemiluminescence assay (Roche Diagnostics Ltd, Mannheim, Germany). The serum level of HBV DNA was assayed by a fluorescent quantitative detection kit ( $\mathrm{Da}$ An Gene, Guangzhou, China). ALT, aspartate aminotransferase (AST), TBIL, serum Cr, albumin (ALB), prothrombin activity (PTA), and INR were measured by routine laboratory methods. MELD scores were calculated according to the Malinchoc formula: $R=9.57 \times \ln [$ creatinine $(\mathrm{mg} / \mathrm{dL})]+3.78 \times \ln [$ bilirubin $(\mathrm{mg} / \mathrm{dL})]+11.2 \times \ln (\mathrm{INR})+6.43 \times($ etiology: 0 if cholestatic or alcoholic, 1 otherwise) [36].

\section{Statistical analysis}

All data were analyzed using SPSS 17.0 software (SPSS Inc., Chicago, IL, USA). Comparison of methylation status among different groups was analyzed by chi-square test or Fisher's exact test. Changes in mRNA concentration were measured by Student $t$ test or Mann-Whitney $U$ test. Spearman test was applied for correlation analysis. Survival curves for methylated group and unmethylated group of ACHBLF patients were compared by Log-rank test. All statistical analyses were two-sided and $P$ value $<0.05$ was considered statistically significant.

\section{Additional files}

Additional file 1: Figure S1. Flowchart of subjects selection. The process of inclusion and exclusion of subjects is shown. (DOC $30 \mathrm{~kb}$ )

Additional file 2: Figure S2. Schematic figure of peroxisome proliferator-activated receptor gamma (PPAR- $\gamma$ ) gene promoter. CpG sites are shown as short vertical lines across the horizontal line. Positions of primers for methylation-specific PCR (MSP) were noted. (TIFF 839 kb)

Additional file 3: Table S1. Primers for methylation-specific PCR (MSP) and quantitative real-time PCR (RT-PCR). The sequence, production size and annealing temperature are shown. (DOC $31 \mathrm{~kb}$ )

\section{Abbreviations}

ACHBLF: acute-on-chronic hepatitis B liver failure; ALB: albumin; ALT: alanine aminotransferase; AST: aspartate aminotransferase; CHB: chronic hepatitis B; Cr: creatinine; HBeAg: hepatitis B e antigen; HBsAg: hepatitis B s antigen; HBV: hepatitis B virus; INR: international normalized ratio; MELD: model for end-stage liver diseases; PBMC: peripheral blood mononuclear cell; PPARY: peroxisome proliferator-activated receptor gamma; PTA: prothrombin activity; TBIL: total bilirubin.

\section{Competing interest}

The authors declare that they have no competing interests.

\section{Authors' contributions}

The study was conceived and designed by KW, ZHZ, and QZ. Participant recruitment was conducted by $Z \mathrm{HZ}, \mathrm{CYD}, \mathrm{XFJ}, \mathrm{JZ}, \mathrm{SG}$, and $\mathrm{XYL}$. The experiments were performed by ZHZ, QZ, CYD, and XFJ. Data were analyzed by ZHZ, YCF, and SG. The paper was written by ZHZ and YCF in communication with KW. All authors read and approved the final manuscript.

\section{Acknowledgements}

This study was funded by grants from Key Project of Chinese Ministry of Science and Technology (2012ZX10002007, 2013ZX10002001), National Natural Science Foundation of China (81171579,81201287,81371832), and Science and Technology Development Plan of Shandong Province (2014GSF118068).

\section{Author details}

'Department of Hepatology, Qilu Hospital of Shandong University, Wenhuaxi Road 107\#, Jinan 250012, China. ${ }^{2}$ Institute of Hepatology, Shandong University, Wenhuaxi Road 107\#, Jinan 250012, China. ${ }^{3}$ Department of Gastroenterology, Provincial Hospital Affiliated to Shandong University, Jinan 250012, China.

Received: 17 July 2015 Accepted: 14 October 2015

Published online: 28 October 2015

\section{References}

1. Liaw YF, Chu CM. Hepatitis B virus infection. Lancet (London, England). 2009;373(9663):582-92. doi:10.1016/s0140-6736(09)60207-5.

2. Sarin SK, Kumar A, Almeida JA, Chawla YK, Fan ST, Garg H, et al. Acute-on-chronic liver failure: consensus recommendations of the Asian Pacific Association for the study of the liver (APASL). Hepatol Int. 2009;3(1):269-82. doi:10.1007/s12072-008-9106-X.

3. Ambrosino G, Naso A, Feltracco P, Carraro P, Basso SM, Varotto S, et al. Cytokines and liver failure: modification of TNF- and IL-6 in patients with acute on chronic liver decompensation treated with molecular adsorbent recycling system (MARS). Acta Bio-Medica Atenei Parmensis. 2003;74 Suppl 2:7-9. 
4. Leifeld L, Cheng S, Ramakers J, Dumoulin FL, Trautwein C, Sauerbruch T, et al. Imbalanced intrahepatic expression of interleukin 12, interferon gamma, and interleukin 10 in fulminant hepatitis B. Hepatology (Baltimore, Md). 2002;36(4 Pt 1):1001-8. doi:10.1053/jhep.2002.35532.

5. Zou Z, Li B, Xu D, Zhang Z, Zhao JM, Zhou G, et al. Imbalanced intrahepatic cytokine expression of interferon-gamma, tumor necrosis factor-alpha, and interleukin-10 in patients with acute-on-chronic liver failure associated with hepatitis B virus infection. J Clin Gastroenterol. 2009;43(2):182-90. doi:10.1097/MCG.0b013e3181624464.

6. Rolando N, Wade J, Davalos M, Wendon J, Philpott-Howard J, Williams R. The systemic inflammatory response syndrome in acute liver failure. Hepatology (Baltimore, Md). 2000;32(4 Pt 1):734-9. doi:10.1053/ jhep.2000.17687.

7. Schoonjans K, Martin G, Staels B, Auwerx J. Peroxisome proliferator-activated receptors, orphans with ligands and functions. Curr Opin Lipidol. 1997;8(3):159-66.

8. Lemberger T, Desvergne B, Wahli W. Peroxisome proliferator-activated receptors: a nuclear receptor signaling pathway in lipid physiology. Annu Rev Cell Dev Biol. 1996;12:335-63. doi:10.1146/annurev.cellbio.12.1.335.

9. Fajas L, Auboeuf D, Raspe E, Schoonjans K, Lefebvre AM, Saladin R, et al. The organization, promoter analysis, and expression of the human PPARgamma gene. J Biol Chem. 1997;272(30):18779-89.

10. Schoonjans K, Staels B, Auwerx J. Role of the peroxisome proliferator-activated receptor (PPAR) in mediating the effects of fibrates and fatty acids on gene expression. J Lipid Res. 1996;37(5):907-25.

11. Schoonjans K, Staels B, Auwerx J. The peroxisome proliferator activated receptors (PPARS) and their effects on lipid metabolism and adipocyte differentiation. Biochim Biophys Acta. 1996;1302(2):93-109.

12. Saltiel AR, Olefsky JM. Thiazolidinediones in the treatment of insulin resistance and type II diabetes. Diabetes. 1996;45(12):1661-9.

13. Ricote M, Li AC, Willson TM, Kelly CJ, Glass CK. The peroxisome proliferatoractivated receptor-gamma is a negative regulator of macrophage activation. Nature. 1998;391(6662):79-82. doi:10.1038/34178.

14. Jiang C, Ting AT, Seed B. PPAR-gamma agonists inhibit production of monocyte inflammatory cytokines. Nature. 1998;391(6662):82-6. doi:10.1038/34184.

15. Standiford TJ, Keshamouni VG, Reddy RC. Peroxisome proliferator-activated receptor-\{gamma\} as a regulator of lung inflammation and repair. Proc Am Thorac Soc. 2005;2(3):226-31. doi:10.1513/pats.200501-010AC.

16. Ramakers JD, Verstege MI, Thuijls G, Te Velde AA, Mensink RP, Plat J. The PPARgamma agonist rosiglitazone impairs colonic inflammation in mice with experimental colitis. J Clin Immunol. 2007;27(3):275-83. doi:10.1007/ s10875-007-9074-2

17. Xu P, Lou XL, Chen C, Yang ZW. Effects of peroxisome proliferator-activated receptor-gamma activation on apoptosis in rats with acute pancreatitis. Dig Dis Sci. 2013;58(12):3516-23. doi:10.1007/s10620-013-2842-3.

18. Zhao Q, Fan YC, Zhao J, Gao S, Zhao ZH, Wang K. DNA methylation patterns of peroxisome proliferator-activated receptor gamma gene associated with liver fibrosis and inflammation in chronic hepatitis B. J Viral Hepat. 2013;20(6):430-7. doi:10.1111/jvh.12048.

19. Kang GH. CpG island hypermethylation in gastric carcinoma and its premalignant lesions. Korean J Pathol. 2012;46(1):1-9. doi:10.4132/ KoreanJPathol.2012.46.1.1.

20. Saxonov S, Berg P, Brutlag DL. A genome-wide analysis of CpG dinucleotides in the human genome distinguishes two distinct classes of promoters. Proc Natl Acad Sci U S A. 2006;103(5):1412-7. doi:10.1073/ pnas.0510310103.

21. Yu J, Ni M, Xu J, Zhang H, Gao B, Gu J, et al. Methylation profiling of twenty promoter-CpG islands of genes which may contribute to hepatocellular carcinogenesis. BMC Cancer. 2002;2:29.

22. Muto Y, Nouri-Aria KT, Meager A, Alexander GJ, Eddleston AL, Williams R. Enhanced tumour necrosis factor and interleukin-1 in fulminant hepatic failure. Lancet (London, England). 1988;2(8602):72-4.

23. de la Mata M, Meager A, Rolando N, Daniels HM, Nouri-Aria KT, Goka AK, et al. Tumour necrosis factor production in fulminant hepatic failure: relation to aetiology and superimposed microbial infection. Clin Exp Immunol. 1990;82(3):479-84.

24. Rolando N, Harvey F, Brahm J, Philpott-Howard J, Alexander G, Gimson A, et al. Prospective study of bacterial infection in acute liver failure: an analysis of fifty patients. Hepatology (Baltimore, Md). 1990;11(1):49-53.
25. Salmeron JM, Tito L, Rimola A, Mas A, Navasa MA, Llach J, et al. Selective intestinal decontamination in the prevention of bacterial infection in patients with acute liver failure. J Hepatol. 1992;14(2-3):280-5.

26. Waage A, Halstensen A, Espevik T. Association between tumour necrosis factor in serum and fatal outcome in patients with meningococcal disease. Lancet (London, England). 1987;1(8529):355-7.

27. Gazzard BG, Portmann B, Murray-Lyon IM, Williams R. Causes of death in fulminant hepatic failure and relationship to quantitative histological assessment of parenchymal damage. Q J Med. 1975;44(176):615-26.

28. Kim HY, Jhun JY, Cho ML, Choi JY, Byun JK, Kim EK, et al. Interleukin-6 upregulates Th17 response via mTOR/STAT3 pathway in acute-on-chronic hepatitis B liver failure. J Gastroenterol. 2014;49(8):1264-73. doi:10.1007/ s00535-013-0891-1.

29. Suh N, Wang Y, Honda T, Gribble GW, Dmitrovsky E, Hickey WF, et al. A novel synthetic oleanane triterpenoid, 2-cyano-3,12-dioxoolean-1,9-dien-28-oic acid with potent differentiating, antiproliferative, and anti-inflammatory activity. Cancer Res. 1999:59(2):336-41.

30. Bordji K, Grillasca JP, Gouze JN, Magdalou J, Schohn H, Keller JM, et al. Evidence for the presence of peroxisome proliferator-activated receptor (PPAR) alpha and gamma and retinoid Z receptor in cartilage. PPARgamma activation modulates the effects of interleukin-1 beta on rat chondrocytes. J Biol Chem. 2000;275(16):12243-50.

31. Miyahara T, Schrum L, Rippe R, Xiong S, Yee Jr HF, Motomura K, et al. Peroxisome proliferator-activated receptors and hepatic stellate cell activation. J Biol Chem. 2000;275(46):35715-22. doi:10.1074/jbc.M006577200.

32. Song $K$, Han C, Zhang J, Lu D, Dash S, Feitelson M, et al. Epigenetic regulation of MicroRNA-122 by peroxisome proliferator activated receptor-gamma and hepatitis $b$ virus $X$ protein in hepatocellular carcinoma cells. Hepatology (Baltimore, Md). 2013;58(5):1681-92. doi:10.1002/hep.26514.

33. Peyrou M, Ramadori P, Bourgoin L, Foti M. PPARs in liver diseases and cancer: epigenetic regulation by microRNAs. PPAR Res. 2012;2012:757803. doi:10.1155/2012/757803.

34. Mann J, Chu DC, Maxwell A, Oakley F, Zhu NL, Tsukamoto H, et al. MeCP2 controls an epigenetic pathway that promotes myofibroblast transdifferentiation and fibrosis. Gastroenterology. 2010;138(2):705-14. doi:10.1053/j.gastro.2009.10.002. 14.e1-4.

35. Lok AS, McMahon BJ. Chronic hepatitis B: update 2009. Hepatology (Baltimore, Md). 2009;50(3):661-2. doi:10.1002/hep.23190.

36. Malinchoc M, Kamath PS, Gordon FD, Peine CJ, Rank J, ter Borg PC. A mode to predict poor survival in patients undergoing transjugular intrahepatic portosystemic shunts. Hepatology (Baltimore, Md). 2000;31(4):864-71. doi:10.1053/he.2000.5852.

\section{Submit your next manuscript to BioMed Central and take full advantage of:}

- Convenient online submission

- Thorough peer review

- No space constraints or color figure charges

- Immediate publication on acceptance

- Inclusion in PubMed, CAS, Scopus and Google Scholar

- Research which is freely available for redistribution

Submit your manuscript at www.biomedcentral.com/submit
C Biomed Central 